\title{
Polymorphisms in the neurogenin 3 gene (NEUROG) and their relation to altered insulin secretion and diabetes in the Danish Caucasian population
}

\author{
J. N. Jensen, L. Hansen, C. T. Ekstrøm, F. Pociot, J. Nerup, T. Hansen, O. Pedersen \\ Steno Diabetes Center, Niels Steensens Vej 2, DK-2820 Gentofte, Copenhagen, Denmark
}

\section{Abstract}

Aim/hypothesis. Neurogenin 3 (NEUROG3) is a member of the subfamily of basic-helix-loop-helix (bHLH) transcription factors involved in differentiation of the endocrine pancreas and therefore a possible candidate gene for maturity-onset diabetes of the young (MODY) and Type II (non-insulin-dependent) diabetes mellitus.

Methods. Using Polymerase-chain-reaction singlestranded-conformation polymorphism, we examined the coding region including the 5'-untranslated and 3'- untranslated regions of the NEUROG3 in a group of 133 diabetic patients comprising 19 MODY patients, 19 patients with dominant Type I diabetes, and 31 early-onset and 64 late-onset Type II diabetic patients.

Results. We found two missense mutations, Gly167Arg and Ser199Phe, as well as two non-coding variants in the 5' UTR, a $\mathrm{c} \rightarrow \mathrm{t}$ nucleotide variant at position -10 upstream of the start codon in one MODY patient and a 2 base pair (CA) deletion poly- morphism at position $-44 /-45$. Allele frequencies measured in 377 diabetic patients and in 217 glucose-tolerant control subjects were: Gly167Arg, 0.04 (95\% CI: 0.02-0.06) and 0.04 (0.02-0.06); Ser199Phe, $0.31(0.26-0.36)$ and $0.30(0.24-0.36) ;-44-45 d e l C A$, $0.33(0.31-0.35)$ and $0.35(0.32-0.38)$, respectively. Both Ser199Phe and the -44-45delCA were in linkage disequilibrium $\left(\chi^{2}>60\right)$ but the Ser199Phe and the -44-45delCA polymorphism were not associated with consistent changes in fasting- or glucose-induced insulin secretion in 249 glucose-tolerant offspring (first-degree relatives) of Type II diabetic parents or in 217 unrelated middle-aged glucose tolerant subjects.

Conclusion/interpretation. Genetic variability in NEUROG3 is not associated with dominant Type I diabetes, MODY, Type II diabetes or changes in insulin secretion in the Danish Caucasians examined subjects. [Diabetologia (2001) 44: 123-126]

Keywords NEUROG3, MODY, mutations, insulin secretion.
Variations in transcription factors expressed in the pancreatic beta cells are involved in the pathogenesis of distinct subsets of Type II (non-insulin-dependent) diabetes mellitus. These transcription factors include the hepatocyte nuclear factor (HNF)- $4 \alpha, \mathrm{HNF}-1 \alpha$,

Received: 19 May 2000 and in revised form 12 September 2000

Corresponding author: L. Hansen, MD, Steno Diabetes Center, Niels Steensens Vej 2, DK-2820 Gentofte, Copenhagen, Denmark

Abbreviations: SSCP, single stranded conformation polymorphism; PCR, polymerase chain reaction.
HNF-1 $\beta$, the insulin promotor factor (IPF)- 1 and neuronal determation factor (NeuroD). The NEU$R O G 3$ is a new member of the subfamily of basic-helix-loop-helix (bHLH) class B transcription factors involved in triggering NeuroD expression in the endocrine pancreatic precursor cells. Thus, NEUROG3 functions as a 'pro-endocrine' switch involved in controlling the development of pancreatic endocrine and exocrine cells [1]. NEUROG3 knockout mice seem normal at birth but die from diabetes within a few days due to a lack of pancreatic endocrine cells. These mice also lack the expression of Pax4, Pax6 and NeuroD, providing further evidence that NEU- 
Table 1. Nucleotide sequences of DNA primers used for PCR amplification of the NEUROG3 gene segments for SSCP-heteroduplex gel analysis and sequencing of variants

\begin{tabular}{lll}
\hline Sense primer (5’-3') & antisense $\left(5^{\prime}-3^{\prime}\right)$ & $\left(\mathrm{T}_{\text {anneal }} / \mathrm{MgCl}_{2}\right)$ \\
\hline 1a: GGA CTC AAA CTT ACC CTT C & 1b: CCT TCT TTC GCC GAC TCC & $58^{\circ} \mathrm{C} / 2.5 \mathrm{mmol} / \mathrm{l}^{\mathrm{b}}$ \\
2a: GAC GCA GCC GGC CTA AGA GC & 2b: AGC GCG TAC AAG CTG TGG TC & $55^{\circ} \mathrm{C} / 1.5 \mathrm{mmol} / 1$ \\
3a: GAC TCA AAC GCT GCG CAT AG & 3b: CTC TCC CTT ACC CTT AGC AC & $60^{\circ} \mathrm{C} / 1.5 \mathrm{mmol} / \mathrm{l}^{\mathrm{b}}$ \\
4a: CTC CTT TGG GGC TGG GGC CAA C & 4b: GGG TTG AGG CGT CAT CCT AC & $60^{\circ} \mathrm{C} / 1.5 \mathrm{mmol}^{\mathrm{a}} / \mathrm{l}$ \\
5a: TGA AAG GAC CTG TCT GCT GTC G & 5b: GCA GAG AGG AGG CCT AAA ATG & $55^{\circ} \mathrm{C} / 1.5 \mathrm{mmol} / 1$ \\
6a: CTC CTT TGG GGC TGG GGC AAC & 6b: GGG TTG AGG CGT CAT CCT AC & $60^{\circ} \mathrm{C}^{\mathrm{a}} 1.5 \mathrm{mmol} / 1$ \\
7a: TGA GAA AGG ACC TGT CTG TCG & 7b: GCA GAG AGG AGG CCT AAA ATG & $55^{\circ} \mathrm{C} / 1.5 \mathrm{mmol} / 1$ \\
\hline
\end{tabular}

PCR conditions: initial denaturation at $94^{\circ} \mathrm{C}$ for $2 \mathrm{~min}, 35 \mathrm{cy}$ cles of denaturation at $94^{\circ} \mathrm{C}, 30 \mathrm{~s}$, annealing $30 \mathrm{~s}$, elongation for $30 \mathrm{~s}$ at $72^{\circ} \mathrm{C}$, and final elongation at $72^{\circ} \mathrm{C}$ for nine min. The annealing temperature and the final $\mathrm{MgCl}_{2}$ concentrations are given in the Table.

ROG3 is the "upstream" pro-endocrine switch controlling the fate of endocrine cells [1]. In view of the key role NEUROG3 has in the differentiation of the endocrine pancreas and that disruption of the $N E U$ ROG3 in mice results in diabetes, NEUROG3 might be a determinant for the pancreatic beta-cell mass and therefore play a part in the pathogenesis of MODY and other subsets of diabetes. We therefore examined the coding region and UTR regions of the NEUROG3 for variability in patients with MODY, Type I (insulin-dependent) diabetes mellitus in three consecutive generations, and in both early-onset and late-onset Type II diabetes.

\section{Subjects and methods}

Subjects. Diabetes mellitus was in all subjects diagnosed in accordance to the 1985 World Health Organisation criteria. Nineteen newly referred MODY patients and 19 patients previously diagnosed as Type I diabetic had a family history of diabetes in three consecutive generations. A further 31 patients were diagnosed as having early-onset Type II diabetes (diabetes diagnosed before the age of 42 years), and finally 64 late-onset Type II diabetic patients with clinical onset after the age of 42 years were included in the primary mutation analysis. The patients were recruited from either the Danish family resource bank at the Department of Human Genetics (University of Copenhagen) or the outpatient clinic at Steno Diabetes Center. Association studies were carried out in 377 patients with Type II diabetes age $61 \pm 11$ years, age at clinical onset of diabetes $55 \pm 5$ years, BMI, $29 \pm 5 \mathrm{~kg} / \mathrm{m}^{2}, 28 \%$ diet treated, $58 \%$ treated with sulphonylurea or biguanide or both, and $14 \%$ treated with insulin as well as in 217 unrelated glucose-tolerant middle-aged control subjects. A phenotype-genotype study to asses the effect of genetic variation on insulin secretion comprised 249 glucose-tolerant offspring of Type II diabetes parents (first-degree relatives) and the 217 middle-aged glucose tolerant subjects from the association study. All the subjects examined declared themselves to be Danish Caucasians. Informed consent was obtained from all the study participants. The protocol was approved by the ethics committee of Copenhagen and was in accordance with the Helsinki Declaration II.

\author{
${ }^{a}$ indicates primers also used for sequencing \\ $\mathrm{b}$ indicates DMSO added to a final concentration of $5 \%$ in the \\ $\mathrm{PCR}$ reaction
}

Genetic analyses. Genomic DNA was prepared from peripheral blood leucocytes as described previously [2]. Mutationl analysis of the NEUROG3 coding region including both 5'-UTR and 3'-UTR sequences in one exon, was carried out by polymerase-chain-reaction single-stranded-conformation-polymorphism (PCR-SSCP) and heteroduplex analysis under two different experimental conditions [2]. We analysed seven segments ranging in size from 225 to 310 base pairs, on $100 \mathrm{ng}$ of genomic DNA as described previously [2]. The primers listed in Table 1 were designed from the genomic sequence (Genbank accession no AJ133776). The variants identified were sequenced using an ABI 377 automated sequencer (Perkin Elmer, Forster City, Ca, USA).

Genotyping of the Ser199Phe and Gly167Arg variants was carried out by PCR amplification of segment 3 using primers $3 a+3 b$ and restriction fragment length polymorphism (RFLP) analysis using EarI for the Ser199Phe variant and SmaI for the Gly167Arg variant as restriction enzymes. Primers $1 \mathrm{a}+1 \mathrm{~b}$ and PCR-RFLP with restriction enzyme $B$ slI were used to test the segregation of the $-10 \mathrm{c} / \mathrm{t}$ nucleotide change with MODY and PCR-SSCP were used in the association studies to examine the $-44 /-45$ variant with Type II diabetes and changes in glucose-induced insulin secretion. The digested fragments were loaded on a $3 \%$ agarose gel and visualised by staining with ethidium bromide.

Biochemical assays and physiological characterization. Plasma glucose, serum insulin and serum $\mathrm{C}$ peptide were analysed using Steno Diabetes Center standard methods. Glucose was measured using a glucose oxidase method. Serum insulin was determined by enzyme-linked immunoassay with narrow specificity excluding des 31,32 and intact proinsulin and serum C peptide was determined by radioimmunoassay using polyclonal antibody M1230. All physiological examinations were done in the morning after a 12 -h overnight fast.

Statistical analysis. Fishers exact test as implemented in AssoTest ver. $04 \mathrm{a}$, was applied to asses any significant difference in allele frequencies, and $\chi^{2}$-analysis of $3 \cdot 3$ contingency table was used to test for linkage disequilibrium. For genotype-phenotype studies, the normal distribution of the residuals was verified visually, and if necessary, logarithmically transformed. The SAS software (ver. 6.12) or Statistical Package of Social Science (SPSS) software for Windows (version 9.0) was used to carry out analysis using a generalized linear model. The analysis included family relation of the offspring, age, BMI, and sex as covariates to compare phenotypic data from the wild-type, heterozygous and homozygous carriers of the Ser199Phe variant. 
Table 2. Clinical and physiological characteristics of 249 glucose tolerant offspring of Type II diabetic parents and 217 unrelated glucose-tolerant control subjects, classified according to their NEUROG3 genotype of the Ser199Phe variant

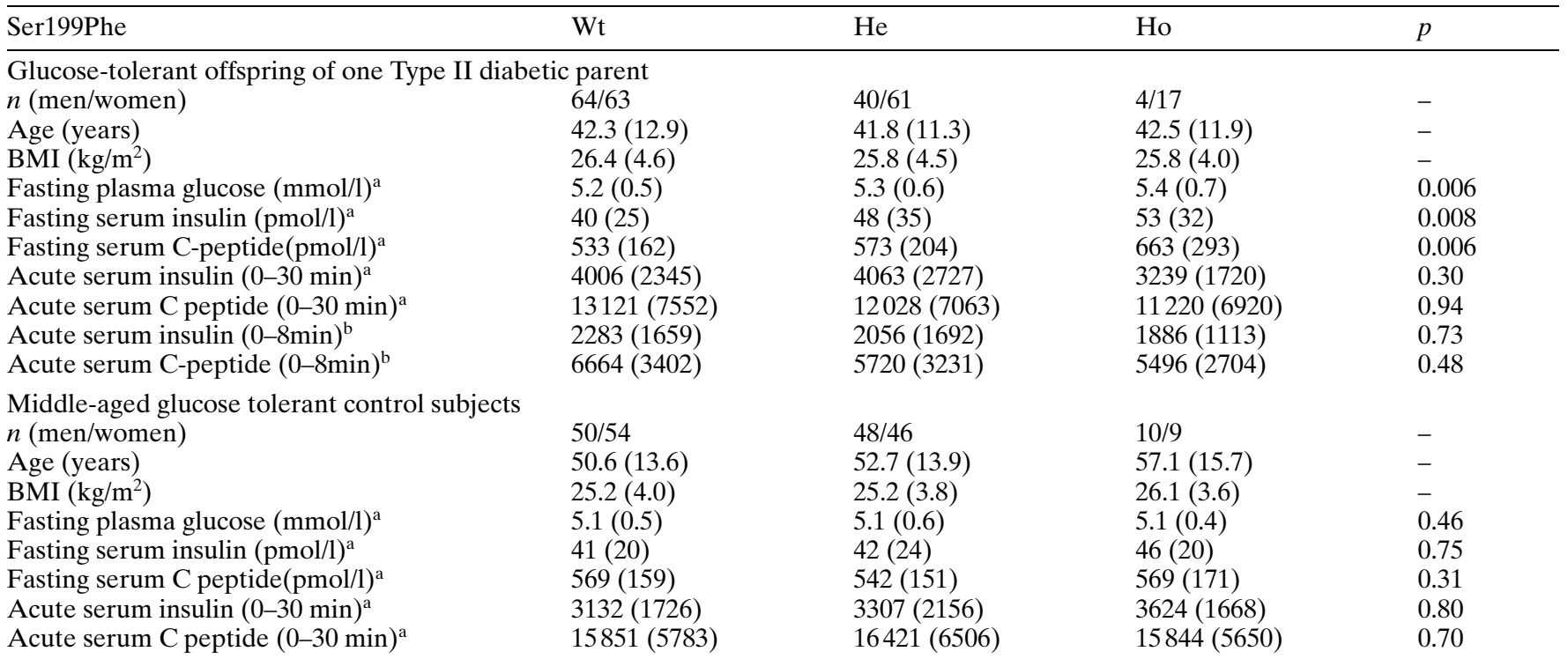

Data represent means (SD). Wt, wild type; He, heterozygote; Ho, homozygote. A generalized linear model was used to compare the wild type, heterozygous, and homozygous carriers. In the analysis, family relation, age, BMI and sex were included as covariates. Due to the lack of statistical power, we did not analyse the Gly167Arg variant. $\mathrm{f}=$ fasting; $\mathrm{s}=$ serum; $p=$ plasma a indicates data from an oral glucose tolerance test (OGTT), acute values are estimated as area under the curve from (0-30 min) after an OGTT

$\mathrm{b}$ indicates values of area under the curve for insulin and Cpeptide secretion from (0-8 min) during an intravenous glucose tolerance test (IVGTT) with $300 \mathrm{mg}$ glucose $/ \mathrm{kg}$ body weight

\section{Results}

Analysis of the coding region of NEUROG3 including the 5'-UTR from position -274 before transtranslation start site and the 3'-UTR region to position +251 after the stop codon revealed in the composite group of diabetes patients (19 dominant type I, 19 MODY probands, 31 early-onset, and 64 with lateonset type II diabetes) two missense mutations, a rare Gly167Arg and a prevalent Ser199Phe variant. Moreover, we discovered two non-coding variants in the 5'UTR. These were a rare $\mathrm{c} \rightarrow \mathrm{t}$ nucleotide variant at position -10 upstream of start codon (ATG) which was only found in one MODY family and a prevalent 2 base pair (CA) deletion at position -44/ -45 . The $-10 \mathrm{C} / \mathrm{T}$ variant did not segregate with diabetes in the MODY family.

The allele frequencies in 377 diabetic patients and 217 glucose tolerant control subjects were: Gly167Arg, 0.04 (95\% CI: 0.02-0.06) and 0.04 (0.02-0.06); Ser199Phe, $0.31(0.26-0.36)$ and 0.30 (0.24-0.36); -44/-45delCA, $0.33(0.31-0.35)$ and 0.35 (0.32-0.38), respectively. The Ser199Phe and $-44 /$ -45 delCA were in linkage disequilibrium $\left(\chi^{2}>60\right)$. Genotype frequencies in patients with Type II diabetes and in control subjects were: Gly167Arg (wt 0.92, he 0.08 vs wt 0.92 , he 0.08); Ser199Phe (wt 0.47, he 0.43 and ho 0.10 vs wt 0.48 , he 0.43 and ho 0.09 ); and

-44/-45delCA (wt 0.46 , he 0.43 and ho 0.11 vs wt 0.44 , he 0.44 and ho 0.12 ), respectively. In addition, we assessed the potential effect of the prevalent Ser199Phe amino-acid substitution on estimates of insulin secretion in 249 glucose-tolerant offspring of Type II diabetic parents. Carriers of the Ser199Phe variant in the offspring of Type II diabetic parents showed a higher fasting plasma glucose $(p=0.006)$, a higher fasting serum insulin $(p=0.008)$, and higher fasting serum $\mathrm{C}$ peptide $(p=0.006)$ (Table 2) compared with the carriers of Ser199Ser. A similar analysis, however, in 217 unrelated glucose-tolerant control subjects failed to show any significant effect of the Ser199Phe variant on insulin secretion (Table 2). The -44/-45delCA was not associated with changes in glucose-induced and fasting serum insulin and $\mathrm{C}$ peptide concentration in the offspring from Type II diabetic parents or in the 217 glucose-tolerant control subjects (data not shown).

\section{Discussion}

The developing pancreas shows time dependent expression of a number of transcription factors such as Pax4, NeuroD, and $\mathrm{Nkx} 2.2$ and at a later stage HNF-4 $\alpha$, HNF-1 $\alpha$, IPF-1, and HNF-1 $\beta$. Mutations in several of these genes cause distinct subtypes of 
MODY. The transcription factor NEUROG3 is an early endocrine marker for the normal development of the pancreas. This suggest that variability in this gene might be essential component in the pathogenesis of diabetes. Because NEUROG3 is located on chromosome 10q, a region associated with Type II diabetes mellitus in Mexican Americans [3], it should also be considered as a positional candidate gene for Type II diabetes. Although several chromosomal loci have been identified by genome-wide linkage studies [3-8], the genetic basis for the common form of late-onset Type II diabetes is not known. Initial results from our mutation analysis and the association studies on the prevalent Ser199Phe and Gly167Arg variants identified indicated that NEUROG3 mutations do not have a role in the pathogenesis of the common form of Type II diabetes. However, because Ser at codon 199 and the Gly at codon 167 are conserved, in mouse, rat and human (data not shown), these gene variants could have a subclinical effect on insulin secretion. In carriers of the codon 199 variant among glucose tolerant offspring of Type II diabetic parent we found higher fasting serum concentrations of insulin and $\mathrm{C}$ peptide at increased fasting plasma glucose. This unexpected finding could not be replicated in middle-aged glucose tolerant subjects and is therefore not considered to be a genuine observation. The non-coding -44/-45delCA variant was in linkage disequilibrium with the Ser199Phe in the coding region of NEUROG3 but it was not associated with differences in insulin or C-peptide secretion in vivo (data not shown).

We report two missense and two non-coding variants in the NEUROG3. Association and genotypephenotype studies suggest that variations in this gene are not likely to be a major cause of Type II diabetes including MODY and dominant Type I diabetes or changes in insulin secretion among glucose tolerant Danish Caucasians.
Acknowledgements. The study was supported by grants from the Danish Medical Research Council, the Velux Foundation, Desirée and Niels Ydes Foundation, the Sehested-Hansen Foundation, the Danish Diabetes Association and the European Union (BMH4-CT-98-3084). The authors thank the Danish Study Group of Diabetes in Childhood, and the Danish IDDM Epidemiology and Genetic Group for providing the families with dominant Type I diabetes and A. Forman, H. Fjordvang, L. Aabo, S. Urioste, B. Mottlau, for their dedicated and careful technical assistance and G. Lademann for secretarial support.

\section{References}

1. Gradwohl G, Dierich A, Lemeur M, Guillemot F (2000) Neurogenin 3 is required for the development of the four endocrine cell lineages of the pancreas. Proc Natl Acad Sci USA 97: 1607-1611

2. Hansen L, Echwald SM, Hansen T, Urhammer SA, Clausen JO, Pedersen O (1997) Amino-acid polymorphisms in the ATP-regulatable inward rectifier KIR6.2 and their relationships to glucose-induced and tolbutamide-induced insulin-secretion, the insulin sensitivity index, and NIDDM. Diabetes 46: 508-512

3. Duggirala R, Blangero J, Almasy L et al. (1999) Linkage of type 2 diabetes mellitus and of age at onset to a genetic location on chromosome $10 \mathrm{q}$ in Mexican Americans. Am J Hum Genet 64: 1127-1140

4. Hanis CL, Boerwinkle E, Chakraborty R et al. (1996) A genome-wide search for human non-insulin-dependent (type2) diabetes genes reveals a major susceptibility locus on chromosome-2. Nat Genet 13: 161-166

5. Mahtani MM, Widen E, Lehto M et al. (1996) Mapping of a gene for type-2 diabetes-associated with an insulin-secretion defect by a genome scan in Finnish families. Nat Genet 14: $90-94$

6. Zouali H, Hani EH, Philippi A et al. (1997) A susceptibility locus for early-onset non-insulin-dependent (type-2) diabetes-mellitus maps to chromosome $20 \mathrm{q}$, proximal to the phosphoenolpyruvate carboxykinase gene. Hum Mol Genet 6: 1401-1408

7. Hanson RL, Ehm MG, Pettitt DJ et al. (1998) An autosomal genomic scan for loci linked to type II diabetes mellitus and body-mass index in Pima Indians. Am J Hum Genet 63: $1130-1138$

8. Ghosh S, Watanabe RM, Hauser ER et al. (1999) Type 2 diabetes: Evidence for linkage on chromosome 20 in 716 Finnish affected sib pairs. Proc Natl Acad Sci USA 96: 2198-2203 